NASA/TM-2005-213990

\title{
Utilizing Radioisotope Power System Waste Heat for Spacecraft Thermal Management
}

David R. Pantano, Frank Dottore, and E. Wayne Tobery

Lockheed Martin Space Systems Company, King of Prussia, Pennsylvania

Steven M. Geng and Jeffrey G. Schreiber

Glenn Research Center, Cleveland, Ohio

Joseph L. Palko

Connecticut Reserve Technologies, Inc., Cleveland, Ohio 
Since its founding, NASA has been dedicated to the advancement of aeronautics and space science. The NASA Scientific and Technical Information (STI) Program Office plays a key part in helping NASA maintain this important role.

The NASA STI Program Office is operated by Langley Research Center, the Lead Center for NASA's scientific and technical information. The NASA STI Program Office provides access to the NASA STI Database, the largest collection of aeronautical and space science STI in the world. The Program Office is also NASA's institutional mechanism for disseminating the results of its research and development activities. These results are published by NASA in the NASA STI Report Series, which includes the following report types:

- $\quad$ TECHNICAL PUBLICATION. Reports of completed research or a major significant phase of research that present the results of NASA programs and include extensive data or theoretical analysis. Includes compilations of significant scientific and technical data and information deemed to be of continuing reference value. NASA's counterpart of peerreviewed formal professional papers but has less stringent limitations on manuscript length and extent of graphic presentations.

- TECHNICAL MEMORANDUM. Scientific and technical findings that are preliminary or of specialized interest, e.g., quick release reports, working papers, and bibliographies that contain minimal annotation. Does not contain extensive analysis.

- CONTRACTOR REPORT. Scientific and technical findings by NASA-sponsored contractors and grantees.
- CONFERENCE PUBLICATION. Collected papers from scientific and technical conferences, symposia, seminars, or other meetings sponsored or cosponsored by NASA.

- SPECIAL PUBLICATION. Scientific, technical, or historical information from NASA programs, projects, and missions, often concerned with subjects having substantial public interest.

- TECHNICAL TRANSLATION. Englishlanguage translations of foreign scientific and technical material pertinent to NASA's mission.

Specialized services that complement the STI Program Office's diverse offerings include creating custom thesauri, building customized databases, organizing and publishing research results ... even providing videos.

For more information about the NASA STI Program Office, see the following:

- Access the NASA STI Program Home Page at http://www.sti.nasa.gov

- E-mail your question via the Internet to help@sti.nasa.gov

- Fax your question to the NASA Access Help Desk at 301-621-0134

- Telephone the NASA Access Help Desk at 301-621-0390

- Write to:

NASA Access Help Desk

NASA Center for AeroSpace Information 7121 Standard Drive

Hanover, MD 21076 
NASA/TM-2005-213990

AIAA-2005-5548

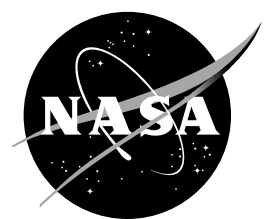

\section{Utilizing Radioisotope Power System Waste Heat for Spacecraft Thermal Management}

David R. Pantano, Frank Dottore, and E. Wayne Tobery

Lockheed Martin Space Systems Company, King of Prussia, Pennsylvania

Steven M. Geng and Jeffrey G. Schreiber

Glenn Research Center, Cleveland, Ohio

Joseph L. Palko

Connecticut Reserve Technologies, Inc., Cleveland, Ohio

Prepared for the

Third International Energy Conversion Engineering Conference sponsored by the American Institute of Aeronautics and Astronautics San Francisco, California, August 15-18, 2005

National Aeronautics and

Space Administration

Glenn Research Center 


\section{Acknowledgments}

This work was enabled through the Department of Energy (DOE) Stirling Radioisotope Generator (SRG110) program. The authors wish to thank James Braun, Jaime Reyes, Robert Cockfield, Dan Tantino, Jack Chan, and Joe Brouch, Lockheed Martin Space Systems Company, King of Prussia, for their support in preparing this paper.

This report is a formal draft or working paper, intended to solicit comments and ideas from a technical peer group.

report contains preliminary findings, subject to revision as analysis proceeds.

Trade names or manufacturers' names are used in this report for identification only. This usage does not constitute an official endorsement, either expressed or implied, by the National Aeronautics and Space Administration.

Available from

NASA Center for Aerospace Information 7121 Standard Drive

Hanover, MD 21076
National Technical Information Service 5285 Port Royal Road Springfield, VA 22100 


\title{
Utilizing Radioisotope Power System Waste Heat for Spacecraft Thermal Management
}

\author{
David R. Pantano, Frank Dottore, and E. Wayne Tobery \\ Lockheed Martin Space Systems Company \\ King of Prussia, Pennsylvania 19406 \\ Steven M. Geng and Jeffrey G. Schreiber \\ National Aeronautics and Space Administration \\ Glenn Research Center \\ Cleveland, Ohio 44135 \\ Joseph L. Palko \\ Connecticut Reserve Technologies, Inc. \\ Cleveland, Ohio 44136
}

\begin{abstract}
An advantage of using a Radioisotope Power System (RPS) for deep space or planetary surface missions is the readily available waste heat, which can be used for a number of beneficial purposes including: maintaining electronic components within a controlled temperature range, warming propulsion tanks and mobility actuators, and maintaining liquid propellants above their freezing temperature. Previous missions using Radioisotope Thermoelectric Generators (RTGs) dissipated large quantities of waste heat due to the low efficiency of the thermoelectric conversion technology. The next generation RPSs, such as the 110-Watt Stirling Radioisotope Generator (SRG110) will have higher conversion efficiencies, thereby rejecting less waste heat at a lower temperature and may require alternate approaches to transferring waste heat to the spacecraft. RTGs, with efficiencies of $\sim 6$ to 7 percent, reject their waste heat at the relatively high heat rejection temperature of $200{ }^{\circ} \mathrm{C}$. This is an advantage when rejecting heat to space; however, transferring heat to the internal spacecraft components requires a large and heavy radiator heat exchanger. At the same time, sensitive spacecraft instruments must be shielded from the thermal radiation of the RTG. The SRG110, with an efficiency around 22 percent and $50{ }^{\circ} \mathrm{C}$ nominal housing surface temperature, can readily transfer the available waste heat directly via heat pipes, thermal straps, or fluid loops. The lower temperatures associated with the SRG110 avoid the chances of overheating other scientific components, eliminating the need for thermal shields. This provides the spacecraft designers more flexibility when locating the generator for a specific mission. A common misconception with high-efficiency systems is that there is not enough waste heat for spacecraft thermal management. This paper will dispel this misconception and investigate the use of a high-efficiency SRG110 for spacecraft thermal management and outline potential methods of waste heat utilization in several conceptual missions (Lunar Rover, Mars Rover, and Titan Lander). The advantages associated with the SRG110 as they relate to ease of assembly, less complex interfaces, and overall mass savings for a spacecraft will be highlighted.
\end{abstract}

\section{Nomenclature}

$\begin{array}{ll}{ }^{\circ} \mathrm{C} & \begin{array}{l}\text { Degrees Celsius } \\ \text { atm }\end{array} \\ \text { atmosphere } \\ \mathrm{BOM} & \begin{array}{l}\text { Beginning of Mission } \\ \mathrm{cm}\end{array} \\ \text { centimeters } \\ \mathrm{g} & \text { gram } \\ \mathrm{kg} & \text { kilogram } \\ \mathrm{kPa} & \text { kilo Pascals }\left(1000 \mathrm{~N} / \mathrm{m}^{2}\right) \\ \mathrm{L} / \mathrm{min} & \text { liters per minute } \\ \mathrm{m} / \mathrm{s} & \text { meters per second } \\ \mathrm{psia} & \text { absolute pressure in pounds per square inch } \\ \mathrm{Pu}^{238} & \text { Plutonium } 238 \\ \mathrm{~W}_{\mathrm{dc}} & \text { Watts electrical Direct Current } \\ \mathrm{W} / \mathrm{kg} & \text { Watts electrical per kilogram }\end{array}$


$\begin{array}{ll}\mathrm{W} / \mathrm{m}^{2} & \text { Watts per square meter } \\ \mathrm{W}_{\mathrm{t}} & \text { Watts thermal }\end{array}$

\section{Introduction}

\section{A. Radioisotope Power Systems}

A Radioisotope Power System (RPS) generates electricity from isotopic decay heat of a Plutonium-238 $\left(\mathrm{Pu}^{238}\right)$ heat source. This heat can be converted into electricity through a number of conversion technologies with the remainder of the thermal energy generally rejected to the environment as wasted energy. RPS systems are used on missions where solar panels would be ineffective e.g., locations with low solar flux at vast distances from the sun or in areas where there is little or no solar insolation for long durations, such as the lunar night or permanently shadowed craters. They are also capable of providing continuous power for very long durations, up to $25+$ years, if necessary. An RPS is a perfect option to provide power for many types of missions including deep space missions, planetary or satellite surface missions, and missions to explore other planets where the spacecraft can take 7 to $10+$ years to reach its destination.

In the past, thermoelectrics have been the only conversion method used on RPSs for deep space and planetary surface missions, such as Pioneer, Voyager, Viking, and Cassini. (ref. 1). The technology of the past 40 years was not capable of efficiencies greater than 7 percent, requiring higher amounts of radioactive fuels to generate relatively small amounts of electrical power (ref. 2). Advancements in mechanical conversion technologies with power systems like the Stirling Radioisotope Generator (SRG110) have led to improved efficiencies, up to 22 percent, thus reducing the fuel required to generate the same amount of electrical power (refs. 3 and 4).

\section{B. Advantages of High-Efficiency Systems}

There are four advantages of high-efficiency systems over low-efficiency systems: lower surface temperature, greater flexibility, lower mission cost, and decreased mass. In general, the low-efficiency systems must operate at high surface temperatures to reject the waste heat without prohibitively large radiator fins. Typical Radioisotope Thermoelectric Generator (RTG) housing surface temperatures, such as those on the General Purpose Heat Source Radioisotope Thermoelectric Generators (GPHS-RTGs) for the Ulysses, Galileo, and Cassini missions, approach $240{ }^{\circ} \mathrm{C}$ while rejecting roughly $4000 \mathrm{~W}_{\mathrm{t}}$ of waste heat (ref. 2). The next generation RTG, the Multi-Mission Radioisotope Thermoelectric Generator (MMRTG) uses a different thermoelectric material and rejects roughly $1900 \mathrm{~W}_{\mathrm{t}}$ of waste heat at a fin root temperature of approximately $200{ }^{\circ} \mathrm{C}$ (ref. 3). While high surface temperatures are an advantage when trying to reject large amounts of heat to the environment, the high surface temperatures present a challenge when the waste heat must be used in a controlled fashion as part of the overall spacecraft thermal management system. A preference for the low-efficiency MMRTG may be partially based on the misconception that there is insufficient waste heat available from high-efficiency systems. This paper addresses this misconception.

\section{Spacecraft Thermal Heating Loads}

Typical deep space or planetary spacecraft heat is provided from electrical heaters and/or Radioisotope Heater Units (RHUs). While Cassini used three RTGs and did receive $\sim 140 \mathrm{~W}_{\mathrm{t}}$ thermal radiation from the RTGs to warm components, it also included electrical heaters and 157 RHUs (35 on Huygens), which provide $1 \mathrm{~W}_{\mathrm{t}}$ each (refs. 5 and 6). The Galileo mission used 2 RTGs, but did not utilize any of the RTG waste heat. Galileo relied on electrical heaters and 120 RHUs to provide thermal power to warm the spacecraft components (ref. 7). The Mars Science Laboratory (MSL), scheduled for launch in 2009, could require up to a maximum of $500 \mathrm{~W}_{\mathrm{t}}$ makeup heat from an RPS to warm the internal components. From these examples, it is reasonable to estimate that most deep space or planetary spacecraft would use at most $500 \mathrm{~W}_{\mathrm{t}}$ of heat for thermal management.

\section{Thermal Advantages}

There are a number of practical ways to harness the waste heat from an RTG, including using radiation exchange from the hot housing surface, high-temperature heat pipes, or a high-temperature forced fluid loop. The high surface temperatures of the RTGs would result in high fluid temperatures if heat pipes or a forced fluid loop were implemented. This would lead to significant thermal design challenges to prevent overheating of the spacecraft components. A heat exchanger simplifies the thermal design, but effectively transferring the waste heat into the spacecraft thermal management system would require a large and heavy 
component. Conversely, the high-efficiency systems such as the SRG110 have housing surface temperatures of $\sim 50{ }^{\circ} \mathrm{C}$ and are more conducive to direct attachment to the spacecraft thermal control system (ref. 4).

Additionally, the high surface temperatures limit acceptable RTG locations and therefore the flexibility of the spacecraft design. At a $200{ }^{\circ} \mathrm{C}$ surface temperature, the radiative flux coming off the RTG surface is roughly $2000 \mathrm{~W} / \mathrm{m}^{2}$. The spacecraft may require thermal shields to protect sensitive instrumentation from these thermal radiation loads. A high-efficiency system with lower surface temperatures may allow the spacecraft designer to locate the power source almost anywhere. In essence, a high-efficiency system facilitates designing the spacecraft without much consideration of the power source, whereas a spacecraft with an RTG must basically be designed around the low-efficiency source.

\section{Reduction in Fuel}

High-efficiency power sources have an obvious advantage in requiring less fuel to generate the same amount of electrical power as compared to their low-efficiency counterparts. The SRG110, for example, offers a four-fold reduction in fuel over the MMRTG. The GPHS heat sources are heavy, $1.6 \mathrm{~kg}$ apiece. The total weight of the heat sources in the MMRTG is almost $13 \mathrm{~kg}$, while only $3.2 \mathrm{~kg}$ for the SRG110. A decrease in mass is transferred directly to the mission in the way of lower mission costs. Furthermore, reducing the mass of the system may enable use of a lighter launch vehicle or increase the payload available for scientific purposes.

\section{Reduction in Required Hardware}

The benefits of a high-efficiency power source extend beyond the savings in fuel. Reductions in hardware as it relates to radiator heat exchangers and thermal shields for sensitive equipment are also possible, thereby reducing cost, design time, testing, and mass. This reduction in hardware can have an effect on the design of the overall system.

In general, when using a low-efficiency power system, the expected environment would define the total area, embedded heat exchanger method, and structural support for the heat exchanger. For example, the heat exchanger would have to be larger for a mission in an extremely cold location such as Titan versus a warmer location like Mars. Due to the easier direct attachment of the thermal control system, such a large and heavy piece of hardware would be completely unnecessary in either location if a high-efficiency system was used instead.

Typically, most thermal shields are carried on solar-powered spacecraft to protect sensitive components from the heat of the sun. While these solar shields would still be necessary in some high-efficiency RPSpowered spacecraft applications, thermal shields would not be necessary to protect onboard components from the heat from the spacecraft's own power source. Cassini, for example, carried three thermal shields, one for each RTG, to protect the scientific payload. The lower surface temperatures of the high-efficiency power source would relax the requirements for these thermal shields, thus providing an opportunity for further program savings.

\section{Spacecraft Thermal Management}

The thermal management of present day spacecraft presents competing challenges between heating and cooling methods in an effort to maintain an acceptable thermal environment for sensitive avionics and instrumentation. Fortunately, to address these challenges, thermal engineers have a variety of thermal management tools at their disposal, including electric heating elements, conducting straps, louvers, heat pipes, fluid loops, etc. However, these challenges may differ depending on the type of mission. For example, thermal management of a spacecraft in Earth orbit may be handled differently than a spacecraft on a deep space mission. For the Earth orbiting spacecraft, options for available thermal energy may extend beyond the onboard source (e.g., solar energy), whereas for a deep space mission, these options become more limited. Because solar panel size must increase exponentially as a function of distance from the sun to generate the same power, when designing for a deep space or planetary surface mission, an alternate power source such as an RPS is generally more effective at generating electrical power than solar energy.

The waste heat from an RPS can be recovered by the spacecraft to provide additional thermal control to the avionics and instrumentation without resorting to additional electrical heaters. Using thermal power to generate electricity, only to then reconvert the electricity back into thermal energy may be a very inefficient use of the limited available spacecraft power. 


\section{Heat Pipes}

Using waste heat from the RPS to directly warm electronics or other spacecraft hardware requires a heat transport device. One such device is a heat pipe. A heat pipe is a self-contained device used to transport heat efficiently across moderate distances. Heat transport is accomplished by the evaporation and condensation of an internal working fluid, which is then recirculated via the capillary action of an internal wick. Heat pipes have been used in a multitude of space applications and are efficient, lightweight, cost effective, and reliable devices. Four different types of heat pipes can be used to transfer and control the amount of heat that is transferred: constant conductance heat pipes (CCHP), variable conductance heat pipes (VCHP), loop heat pipes (LHP), and diode heat pipes.

A CCHP consists of a pipe that is lined with a wick and capped off at both ends. The pipe is completely evacuated prior to being charged with a small amount of working fluid (water and ammonia are among the most efficient at $50{ }^{\circ} \mathrm{C}$ ). When heat is introduced to any spot along the length of the CCHP the working fluid in that location evaporates and then condenses at a colder location along the pipe. Capillary action works to restore equilibrium (i.e., to uniformly saturate the wick) and transports the fluid to any location that has been depleted of its working fluid. CCHPs are often embedded in honeycomb panels as an effective method of isothermalizing the panel. They can be bent into a two or three-dimensional shapes and work best in a zero-g environment or where the effects of gravity are minimized.

If heat were added at one end of a CCHP and removed from the other end, the vapor phase would sweep the entire length of the pipe before condensing and being returned as liquid by the wick. This phenomenon is used to the designers' advantage in a VCHP. A VCHP is a CCHP with a small amount of non-condensable gas introduced along with the working fluid. As the vapor sweeps the entire length of the pipe, it sweeps the non-condensable gas along with it. This gas accumulates as a plug effectively blocking a portion of the condenser. The size of the plug is a function of many factors; however, with the addition of a gas reservoir located at the condenser end, a VCHP can be configured to maintain a specific temperature range in the component in need of temperature stability. Therefore, a VCHP is used when temperature regulation of the heat source is needed.

CCHPs and VCHPs work well in the zero gravity environment of space. They are, however, sensitive to orientation when used in a gravitational field, working fine when completely horizontal and having reduced, or no, capacity in a vertical orientation.

An LHP can best be described as a heat pipe with the functions separated and grouped together. The wick of a CCHP lines the entire length of the heat pipe, whereas an LHP wick is contained in an evaporator 1 to 12 inches $(2.5$ to $30.5 \mathrm{~cm})$ in length, which is then attached to the heat source. The wick is the dividing line between the liquid and vapor phases. One side of the wick is in contact with liquid and the other with vapor. Source heat is transferred into the wick and causes evaporation of the working fluid. The vapor flows into the wickless condenser tube, which can be as small as 0.125 inches $(0.318 \mathrm{~cm})$ in diameter and 100 or more feet $(30.5+\mathrm{m})$ in length. Heat removal can occur uniformly along the entire length of the condenser tube or at a specific location. Either way the vapor is condensed and pushed along by the vapor behind it until it reaches the wick at which point, the cycle is repeated.

A diode heat pipe, as the name suggests, will transfer heat in only one direction. This can be accomplished in one of two ways. By utilizing a gas reservoir, similar to a VCHP but with a smaller amount of non-condensable gas, the heat pipe will function like a normal CCHP when operating in the forward direction. In this mode, the non-condensable gas resides completely within the reservoir. When operated in reverse, the non-condensable gas is swept out of the reservoir and completely fills the working length of the heat pipe blocking operation. A second method is to have a working-fluid trap (i.e., an unwicked reservoir) at the evaporator end. During forward operation no fluid will condense in the reservoir since it is at the same temperature as the evaporator. During reverse operation, the fluid will eventually end up in the reservoir, since there is no wick to bring the fluid back into circulation. When the temperature gradient is reestablished in the forward direction the working fluid evaporates out of the reservoir and the heat pipe is once again fully functional.

Attachment of the heat pipe to the hot and cold surfaces can be accomplished by using a thermally conductive adhesive, press fit, or by clamping. A thermal interface material may be used between the two mating surfaces to enhance conductivity. In a typical RTG application, the heat pipes would be imbedded into the radiator heat exchanger and then routed into the spacecraft. For the higher efficiency systems, the heat pipes could be directly mounted onto the housing surface. 


\section{Louvers and Insulation}

Typically, a spacecraft would be insulated around the primary structure and propulsion system, with penetrations for radiators for heat dissipating electronic components or for instruments. Spacecraft insulation typically consists of multi-layer foils, with the number of layers sized locally to achieve the required effective emissivity. The radiators are sized for maximum heat dissipation and worse case thermal environments. In situations where components are turned off or put in standby mode for power management reasons, louvers may be employed to reduce the effective radiator area by shielding all or part of the radiator surface. The louvers can be actuated passively by temperature changes or actively via electronic controls that sense temperature changes. Typical passive louvers consist of a bi-metal that expands or contracts as temperatures increase or decrease to move some form of a mechanical shield over the areas to be protected.

Similarly, heat sources inside of a spacecraft can vary the amount of heat rejected into the spacecraft for thermal management by using a system of insulation and louvers. When the spacecraft requires more heat for temperature control, the louvers can close retaining more heat inside the spacecraft. Conversely, the louvers can open and reject more heat to the environment when not required.

Louvers and insulation would not be a viable thermal management technique for a low-efficiency RPS due to the amount of waste heat. In most cases, the amount of waste heat generated by a low-efficiency RPS necessitates a cantilever mount from the spacecraft to provide the maximum area possible for heat rejection. However, the high-efficiency systems like the SRG110 could be mounted inside the spacecraft to provide the highest possible waste heat utilization. In this case, variable area radiators and insulation could be used together to effectively maintain components within their allowable flight temperature limits. This flexibility represents one of the distinct advantages with high-efficiency RPS systems.

\section{Forced Fluid Loop}

Another effective means for transferring thermal energy is with a pumped fluid loop. A pump provides the driving force necessary to create fluid flow over a hot surface transferring heat to the fluid and subsequently over another, colder surface that accepts heat from the fluid. A variable speed pump can be included to throttle flow based on temperature requirements of the system. With this type of system, flow is reduced to limit additional heat flow to the hardware in a hot environment, while in a cold environment the flow can be increased to transfer more heat.

A forced fluid loop usually includes a redundant pump system with thin-walled aluminum tubing and, depending on predicted temperatures, a working fluid such as water or a refrigerant. The pump is mounted to the spacecraft and the fluid lines are soldered or brazed onto the hot and cold surfaces. To date, pumped fluid loops have been flown on several missions including the Mars Pathfinder and Mars Exploration Rovers (MER) (refs. 8 to 10). In these cases the working fluid was R-11 pressurized to $100 \mathrm{psia}(690 \mathrm{kPa})$ to preclude formation of a vapor phase. During the cruise phase while in transit to Mars, the fluid carried the waste heat generated by the internal electronics of the lander (which was enclosed in an aeroshell) to an external radiator system to prevent overheating. The currently planned Mars Science Laboratory (MSL) mission will use a similar pumped loop.

A forced fluid loop would be implemented similar to heat pipes. A low-efficiency system would have the tubing installed inside of a radiation heat exchanger, while a high-efficiency system would have the tubing mounted directly to the RPS fins or housing.

\section{Mission Requirements}

Thermal requirements of the various missions can vary depending on the mission profile and objectives. A system designed specifically to maintain acceptable temperatures in the darkness of the interstellar void would overheat if exposed to the $127{ }^{\circ} \mathrm{C}$ daytime temperatures of the lunar surface. The environmental boundary conditions throughout the mission, desired spacecraft size and type, and the special needs of scientific instruments, electronics, augmentation batteries, and propulsion elements all contribute to the mission requirements of the thermal management system. Through use of any one or a combination of the available thermal management techniques described previously, the RPS can be used to maintain the spacecraft components within allowable temperature limits. 

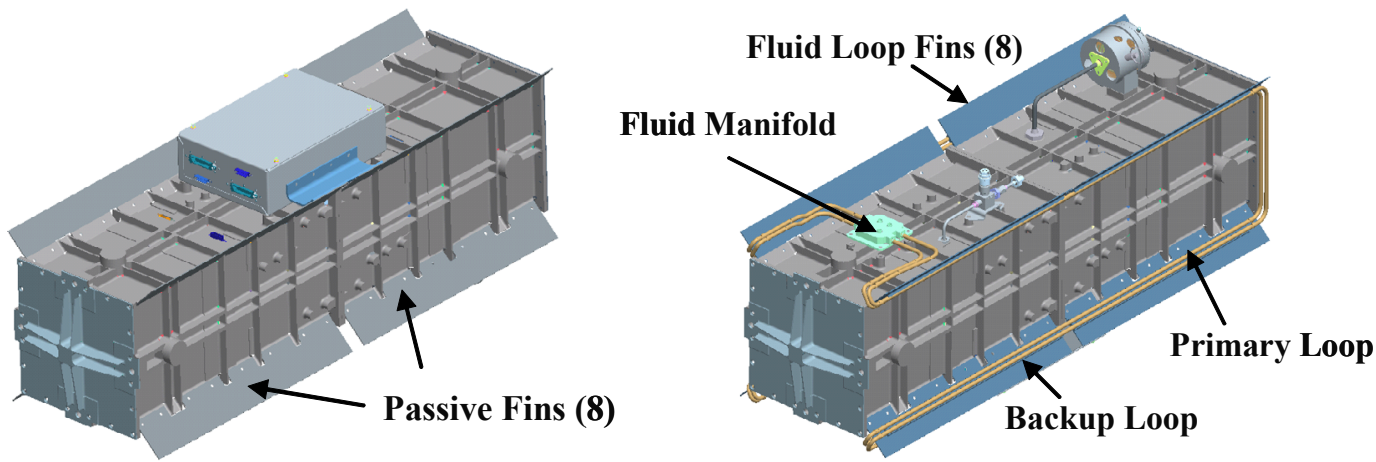

Figure 1.-SRG110 Shown with Reconfigurable Fins.

\section{Interfaces}

The specific spacecraft design and operational environments will dictate the necessary thermal interfaces from the RPS to the spacecraft. A multi-mission power source must be readily adaptable to any spacecraft configuration and not force limitations on the spacecraft design. High-efficiency systems like the SRG110 can be designed with simple and robust interfaces for ease of assembly and integration with the spacecraft. The reconfigurable nature of the detachable SRG110 fins, as shown in figure 1, allow for flexibility in meeting mission requirements. Different fins could be attached for different missions, e.g., radiation fins, fins with forced fluid lines, heat pipes, conduction straps, or fins with a mechanical mounting provision to provide direct conduction to spacecraft components.

Similar techniques could be used for the MMRTG, but implementation would be more challenging. Because of the high temperatures associated with this low-efficiency power source, the MMRTG must use a cantilever mount to locate the power source away from the spacecraft. Due to the quantity of waste heat generated, it would not be possible to completely enclose the MMRTG inside the spacecraft, thereby limiting its positioning flexibility. The high surface temperature would also require that the interfaces, either heat pipes, fluid loops, conduction straps, etc., be capable of withstanding the high temperatures. Most electronic components cannot survive contact with a $200{ }^{\circ} \mathrm{C}$ heat transport device, so considerations would have to be made to material selection, fluid properties, and contact interfaces to prevent the electronics from overheating.

\section{Analysis}

To demonstrate the advantages and flexibility of a reconfigurable, high-efficiency power source, several possible missions were considered where the RPS was used for electrical power and thermal management for spacecraft components. For each example, the SRG110 served as the power source. The assumptions related to the operating conditions and design requirements of the SRG110 appear in table 1. The conditions and design requirements of the MMRTG are also listed in table 1 for comparison (refs. 3, 4, and 12). The information listed in table 1 summarizes the operational performance of each system from presently available public references and does not reflect performance enhancements that may be possible through currently on-going design evolutions.

Three separate and varied missions were selected for the analyses. The missions were selected based on the realistic nature of scientific interest, the amount of environmental information available for each mission, and the fact that together, the environments for the various missions represented a wide spectrum of potential operational conditions for the RPS. The missions included: Lunar Rover, Mars Rover, and Titan Lander. For each of these cases, the spacecraft power requirements at the beginning of mission (BOM) remained the same: $200 \mathrm{~W}_{\mathrm{dc}}$ of electrical power and a variable thermal management heat load of approximately $500 \mathrm{~W}_{\mathrm{t}}$. Achieving this amount of electrical power would require two of the current state-orthe-art RPSs, either MMRTG or SRG110. The environmental factors, and therefore the thermal management requirements, were mission dependent. It should be noted that these three mission profiles represent only a small subset of the capabilities of an SRG110-powered spacecraft. 
Table 1. SRG110 and MMRTG Design Requirements and Operational Condition Assumptions

\begin{tabular}{|l|c|c|}
\hline & SRG110 & MMRTG \\
\hline Typical Efficiency & $22 \%$ & $6 \%$ \\
\hline Conversion Technology & Stirling Engine & $\begin{array}{c}\text { PbTe/TAGS } \\
\text { thermoelectric }\end{array}$ \\
\hline $\begin{array}{l}\text { Nominal Output Power }- \text { BOM Deep } \\
\text { Space Mission }\left(\mathrm{W}_{\mathrm{dc}}\right)\end{array}$ & 116 & 125 \\
\hline Initial Fuel Loading $\left(\mathrm{W}_{\mathrm{t}}\right)$ & 500 & 2000 \\
\hline Typical Surface Temperature $\left({ }^{\circ} \mathrm{C}\right)$ & 50 & 200 \\
\hline Possible Mission Environments & Multi-Mission & Multi-Mission \\
\hline Envelope $(\mathrm{cm})$ & $104 \times 38 \times 29$ & $65 \times 63$ \\
\hline Mass $(\mathrm{kg})$ & 34 & 44 \\
\hline Specific Power $(\mathrm{W} / \mathrm{kg})$ & 3.4 & 2.8 \\
\hline
\end{tabular}

Table 2. Lunar Surface Assumptions

\begin{tabular}{|l|c|c|}
\hline Condition & Hot Case & Cold Case \\
\hline Location & $\begin{array}{c}\text { Lunar Surface } \\
- \text { Direct Sun }\end{array}$ & $\begin{array}{c}\text { Permanently } \\
\text { Dark Crater }\end{array}$ \\
\hline Incident Solar Flux $\left(\mathrm{W} / \mathrm{m}^{2}\right)$ & 1400 & 0 \\
\hline Surface Temperature $\left({ }^{\circ} \mathrm{C}\right)$ & 127 & -190 \\
\hline Surface Emissivity & 0.9 & 0.9 \\
\hline Lunar Dust Absorptance & 0.9 & 0.9 \\
\hline Sky Sink Temperature $\left({ }^{\circ} \mathrm{C}\right)$ & -269 & -269 \\
\hline
\end{tabular}

\section{Lunar Rover}

The Lunar Rover concept considered here was based on two studies by NASA Jet Propulsion Laboratory (JPL) (refs. 11 and 12). These references provided detailed information regarding proposed architecture to enable a successful mission on the lunar surface, with either manned or unmanned vehicles. For the purposes of this investigation, two cases were studied; a hot case, which included direct solar insolation, and a cold case, which represented operation during lunar night or in a permanently shadowed crater. The assumed lunar conditions for these two cases are summarized in table 2 .

\section{Lunar Rover Configuration}

Two SRG110s would be mounted internal to the lunar rover with VCHPs, diode heat pipes, or a pumped fluid loop running from the base of the SRG110 fins to the internal components of the rover. A variable heat transport mechanism would be required to support rover operations in both hot and cold conditions. For this investigation it was assumed that VCHPs would be used to transport the heat from the SRG110s to the rover radiators. 


\section{Lunar Rover Thermal Model}

A thermal model was constructed using Thermal Desktop ${ }^{\circledR}$ (ref. 13) to predict the resulting temperatures and heat transferred to the rover under both environmental conditions. It was assumed that the rover required at least $500 \mathrm{Wt}$ during the cold case and as little as possible during the hot cases. The surface of the Lunar Rover was assumed to be coated with a fine layer of lunar dust. Some form of dust mitigation was assumed, making the optical properties of the exposed surfaces have an emissivity of 0.9 and an absorptivity of $0.5(\varepsilon=0.9$ and $\alpha=0.5)$.

\section{Thermal Analysis Results for Lunar Rover Mission}

The thermal analysis results showed that the temperature difference between the two cases resulted in a challenging thermal management scenario. In the cold case, the analysis showed that the SRG110s could operate within expected design limits and still provide the required thermal and electrical power to the rover through all mission phases. The lunar hot case demonstrated the challenges inherent to lunar operations. In order to develop a common system for both hot and cold operations, compromises were made to optimize the performance for the cold case at the expense of the performance for the hot case. The temperature predictions for the SRG110 and the representation of the rover are shown in figure 2 and summarized in table 3 .

\section{Temperature $\left({ }^{\circ} \mathrm{C}\right)$}

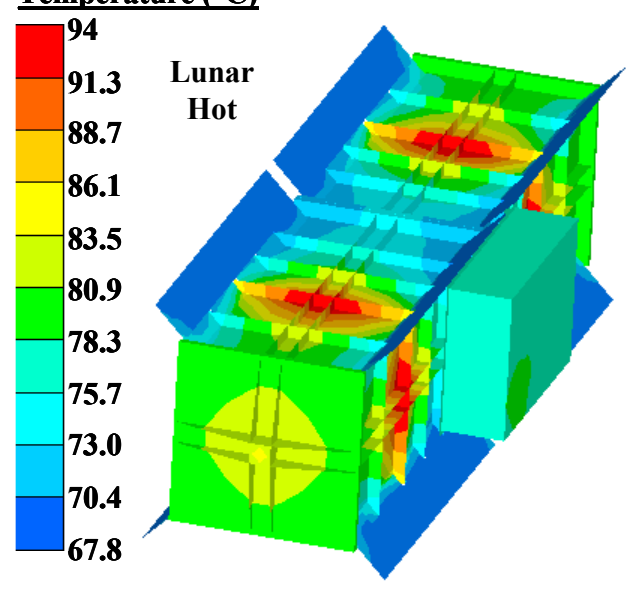

\section{Temperature $\left({ }^{\circ} \mathrm{C}\right.$}

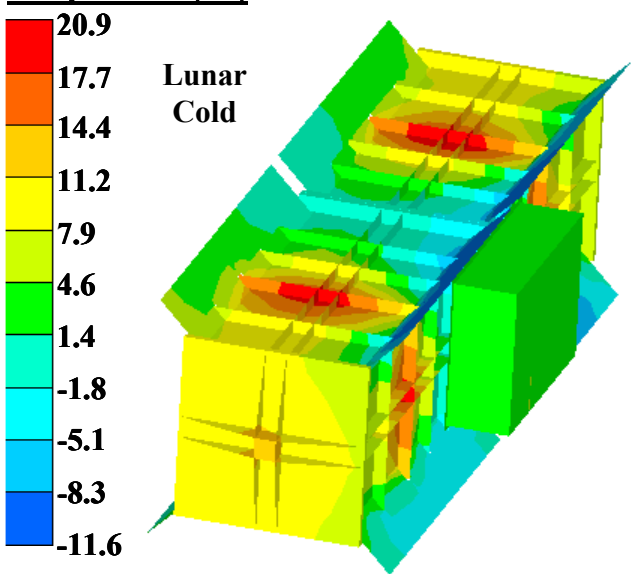

Figure 2.-Temperature Profiles for the SRG110 Lunar Rover Configuration in Hot and Cold Environments.

Table 3. Thermal Analysis Results for the SRG110 Lunar Rover Configuration

\begin{tabular}{|l|c|c|}
\hline Condition & Hot Case & Cold Case \\
\hline $\begin{array}{l}\text { Total Electrical Power - 2 SRG110s } \\
\text { BOM }\left(\mathrm{W}_{\mathrm{dc}}\right)\end{array}$ & 201 & 234 \\
\hline $\begin{array}{l}\text { Waste Heat to Rover - 2 SRG110s } \\
\text { BOM }\left(\mathrm{W}_{\mathrm{t}}\right)\end{array}$ & $76^{*}$ & $610^{* *}$ \\
\hline $\begin{array}{l}\text { Average SRG110 Surface } \\
\text { Temperature }\left({ }^{\circ} \mathrm{C}\right)\end{array}$ & 77 & 5 \\
\hline $\begin{array}{l}\text { Heat Pipe Average Temperature }\left({ }^{\circ} \mathrm{C}\right) \\
\begin{array}{l}\text { Notes: } \\
*\end{array}\end{array}$ & 68 & -12 \\
\hline
\end{tabular}




\section{E. Mars Rover}

In this simulation, SRG110s were applied to a Mars Rover concept. A typical Mars mission can involve wide temperature ranges depending on many factors, including local environmental conditions and landing locations of the spacecraft. By evaluating the SRG110 Mars Rover concept under both hot and cold conditions, missions anywhere within $\pm 60^{\circ}$ latitude on the Mars surface were covered. Table 4 summarizes the assumed conditions for each case.

Table 4.-Mars Surface Conditions Assumed

\begin{tabular}{|l|c|c|}
\hline Condition & Hot Case & Cold Case \\
\hline Location & $15^{\circ}$ South Latitude & $60^{\circ}$ North Latitude \\
\hline Season & Martian Summer & Martian Winter \\
\hline Direct Solar Flux $\left(\mathrm{W} / \mathrm{m}^{2}\right)$ & 580 & 0 \\
\hline Diffuse Solar Flux $\left(\mathrm{W} / \mathrm{m}^{2}\right)$ & 104 & 0 \\
\hline Surface Temperature $\left({ }^{\circ} \mathrm{C}\right)$ & 31 & -123 \\
\hline Surface Emissivity & 0.8 & 0.8 \\
\hline Atmosphere Temperature $\left({ }^{\circ} \mathrm{C}\right)$ & 5 & -123 \\
\hline Sky Sink Temperature $\left({ }^{\circ} \mathrm{C}\right)$ & -101 & -150 \\
\hline Atmosphere Pressure $(\mathrm{kPa})$ & 0.67 & 1.34 \\
\hline Surface Wind Speed $(\mathrm{m} / \mathrm{s})$ & 0 & 30 \\
\hline
\end{tabular}

\section{Mars Rover Configuration}

For the Mars rover mission, it was assumed that two SRG110s were mounted internally on the rover vehicle and coupled with a pumped fluid loop running from the base of the SRG110 fins to the internal components of the rover. It was also assumed that water was the working fluid in the pumped fluid loop at a pressure of 100 psia $(690 \mathrm{kPa})$ with a maximum flow rate of $0.65 \mathrm{~L} / \mathrm{min}$. By mounting the SRG110s internally, the waste heat available for thermal management of the onboard electronics would be maximized, and the SRG110s would be shielded from the Martian wind when exposed to the cold environment. The SRG110s were protected on five sides by the insulated exterior shell of the rover and the sixth side was open to the rover electronics cavity. Not only would this allow easy installation, but also the open side provided a line of sight for thermal radiation to the internal components of the rover. The use of water as the working fluid provided the best heat transfer option when considering heat transport from the SRG110s to the external rover radiators while the rover was exposed to the hot environment. The Mars Rover configuration, based on the Mars Science Laboratory (MSL) design, with the SRG110s is shown in figure 3 .

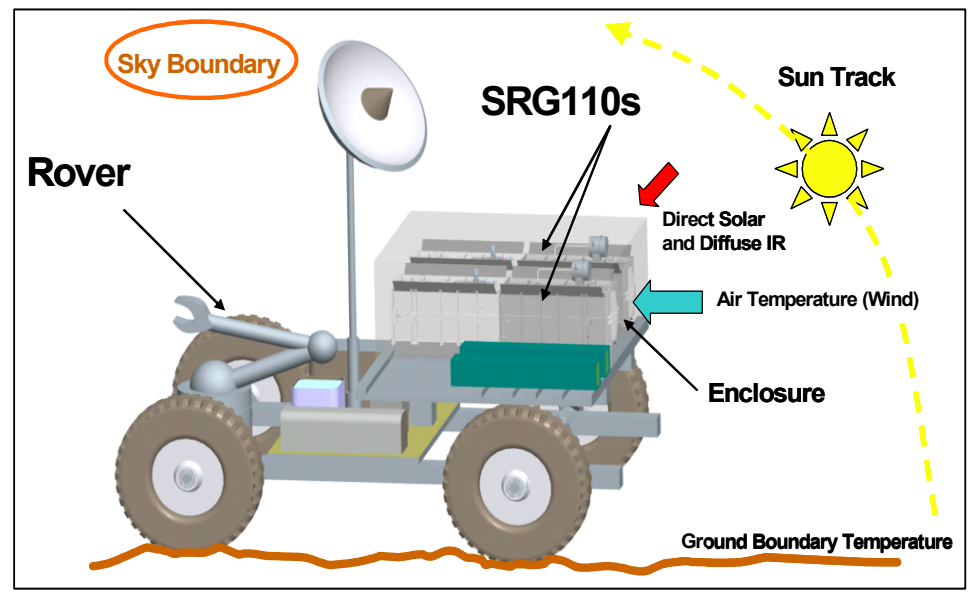

Figure 3.- Mars Rover Configuration with SRG110s. 


\section{Mars Rover Thermal Model}

The thermal model was again constructed using Thermal Desktop ${ }^{\circledR}$ to predict the resulting temperatures and heat transferred to the rover. The different environmental conditions presented different modeling challenges. When exposed to the cold conditions, it was assumed that the rover required approximately $500 \mathrm{~W}_{\mathrm{t}}$ for onboard thermal management. When exposed to the hot environment, it was assumed that all of the waste heat in the pumped fluid loop bypassed the rover internal components and was rejected to the Martian atmosphere. The surface of the rover was assumed to be coated with a fine layer of Martian dust making the optical properties equal to the Martian surface, $\varepsilon=0.8$ and $\alpha=0.8$.

\section{Thermal Analysis Results for Mars Rover Mission}

The thermal analysis results showed that the SRG110s operated within allowable temperature limits and still provided the required thermal and electrical power to the rover through all mission phases. Furthermore, it was demonstrated that the rover fluid cooling system varies by only $32{ }^{\circ} \mathrm{C}$ between the worst-case environmental conditions, demonstrating thermal control capability over the environmental range. The temperature predictions for the SRG110s are shown in figure 4 and summarized in table 5. The total amount of heat transferred to the rover in the cold case was defined as the heat transferred into the working fluid. For the hot case, the heat transmitted to the rover only included the radiative heat transmitted into the rover electronics cavity, as it was assumed that the pumped loop bypassed the rover internal components and transferred the heat instead to the external radiators.
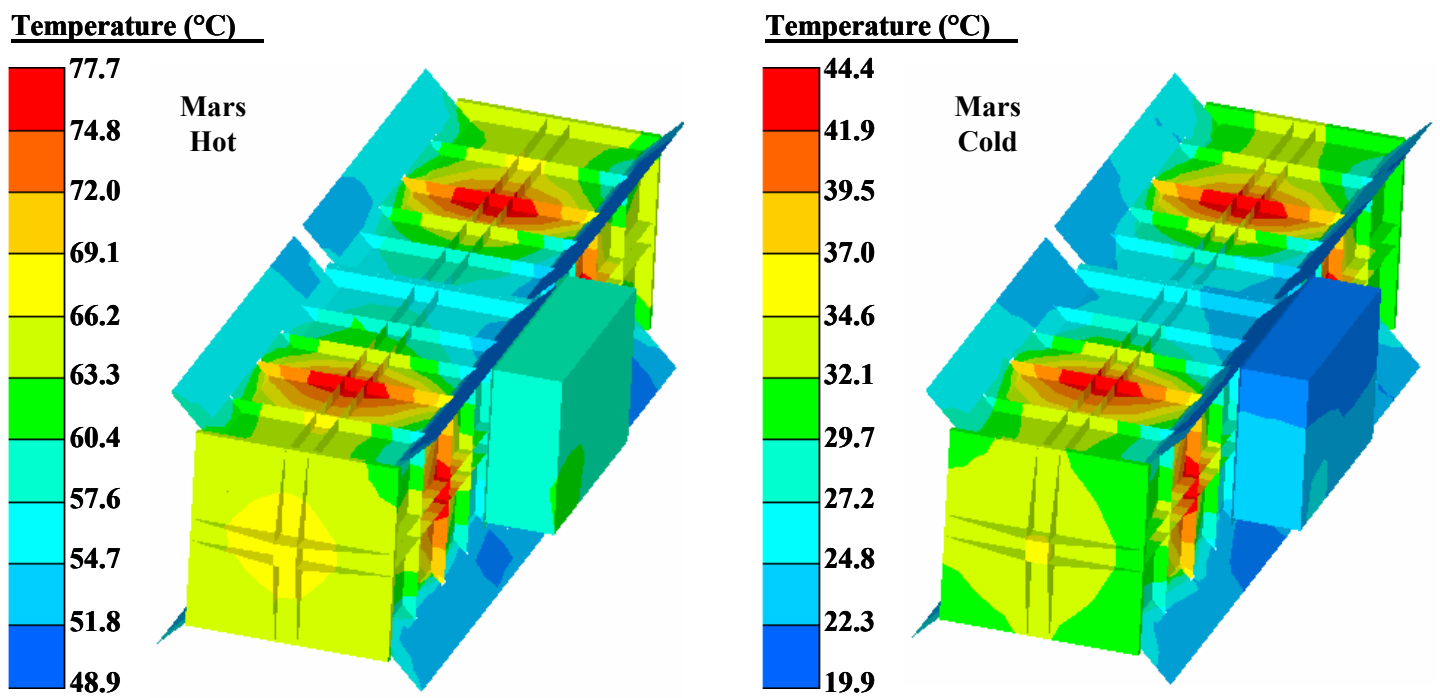

Figure 4.--Temperature Profiles for the SRG110 Mars Rover Configuration in Hot and Cold Environments.

Table 5. Thermal Analysis Results for the SRG110 Mars Rover Configuration

\begin{tabular}{|l|c|c|}
\hline Condition & Hot Case & Cold Case \\
\hline $\begin{array}{l}\text { Total Electrical Power - 2 SRG110s } \\
\text { BOM }\left(\mathrm{W}_{\mathrm{dc}}\right)\end{array}$ & 206 & 216 \\
\hline $\begin{array}{l}\text { Waste Heat to Rover - 2 SRG110s } \\
\text { BOM }\left(\mathrm{W}_{\mathrm{t}}\right)\end{array}$ & $58^{*}$ & $512^{* *}$ \\
\hline $\begin{array}{l}\text { Average SRG110 Surface } \\
\text { Temperature }\left({ }^{\circ} \mathrm{C}\right)\end{array}$ & 62 & 30 \\
\hline $\begin{array}{l}\text { Fluid Temperature into Rover }\left({ }^{\circ} \mathrm{C}\right) \\
\text { Notes: } * \text { Includes radiation only } \\
* * \text { Includes heat transported by pumped fluid loop only }\end{array}$ \\
\hline
\end{tabular}




\section{F. Titan Lander}

As the final example for a possible mission, the Titan Lander concept was considered for the SRG110. Information for this scenario was taken from the recently accomplished Huygens probe mission by the European Space Agency (ESA) and NASA JPL (ref. 6). The Huygens probe was released by the Cassini spacecraft on December 25, 2004, and landed on the Titan surface on January 14, 2005, where it survived for roughly 2 hours before its limited battery power was exhausted. Had the Huygens probe included an RPS system such as the SRG110, its mission could have been extended well beyond 2 hours and much more scientific information could have been retrieved. Titan represents an unusual environment that may include liquid methane and the possibility of hydrocarbon rain. The atmosphere is very thick and for this analysis it was assumed to effectively attenuate the extremely weak solar flux at the surface. The wind speeds in the upper atmosphere have been estimated at approximately $120 \mathrm{~m} / \mathrm{s}$; however, no information was available for the estimated wind speed at the surface. For the purposes of this study, it was assumed that the surface wind speed would be approximately 10 percent of the upper atmosphere wind. The Titan surface conditions assumed for this study are summarized in table 6 .

Table 6. Titan Surface Conditions Assumed

\begin{tabular}{|l|c|}
\hline Condition & Cold Case \\
\hline Location & Surface \\
\hline Direct Solar Flux $\left(\mathrm{W} / \mathrm{m}^{2}\right)$ & 0 \\
\hline Diffuse Solar Flux $\left(\mathrm{W} / \mathrm{m}^{2}\right)$ & 0 \\
\hline Surface Temperature $\left({ }^{\circ} \mathrm{C}\right)$ & -180 \\
\hline Atmospheric Pressure $(\mathrm{kPa})$ & 152 \\
\hline Surface Wind Speed $(\mathrm{m} / \mathrm{s})$ & 12 \\
\hline
\end{tabular}

\section{Titan Lander Configuration}

Like the Mars Rover, the Titan Lander would require an internal mount for two SRG110s. Constant conductance heat pipes (CCHPs) running from the base of the SRG110 fins to the internal components served as the thermal management system for the onboard components. Since it was expected that there was only a "cold" condition on Titan, constant conductance heat pipes or loop heat pipes could be used since the lander's demand for waste heat would be constant. For this investigation it was assumed that the CCHPs would be aluminum with ammonia as the working fluid. Additionally, the SRG110 radiator fins would be as small as possible to minimize the heat transfer to the environment.

\section{Titan Lander Thermal Model}

A thermal model was constructed using Thermal Desktop ${ }^{\circledR}$ to predict the resulting temperatures and heat transferred to the lander. It was assumed that the lander requires approximately $500 \mathrm{~W}_{\mathrm{t}}$ to survive these extremely cold conditions.

\section{Thermal Analysis Results for Titan Lander Mission}

The thermal analysis results showed that the SRG110s operated within allowable temperature limits and still provided the required thermal and electrical power to the lander. The temperature predictions for the SRG110s and the representation of the rover are shown in figure 5 and summarized in table 7. 


\section{$\underline{\text { Temperature }\left({ }^{\circ} \mathbf{C}\right)}$}

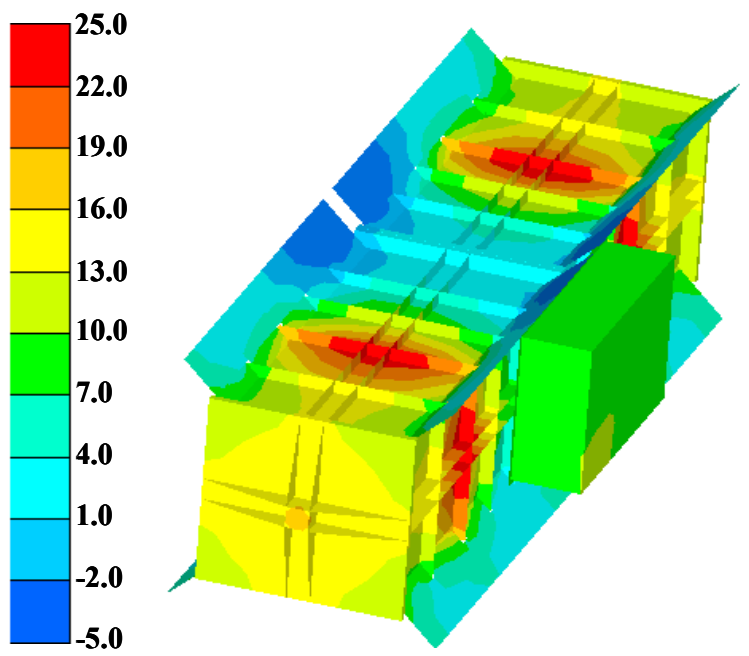

Figure 5.-Temperature Profiles for the SRG110 Titan Lander Configuration.

Table 7. Thermal Analysis Results for the SRG110 Titan Lander Configuration

\begin{tabular}{|l|c|}
\hline Condition & Cold Case \\
\hline Total Electrical Power -2 SRG110s BOM $\left(\mathrm{W}_{\mathrm{dc}}\right)$ & 228 \\
\hline Waste Heat to Lander -2 SRG110s BOM $\left(\mathrm{W}_{\mathrm{t}}\right)$ & $482 *$ \\
\hline Average SRG110 Surface Temperature $\left({ }^{\circ} \mathrm{C}\right)$ & 10 \\
\hline Heat Pipe Average Temperature $\left({ }^{\circ} \mathrm{C}\right)$ & -30 \\
\hline
\end{tabular}

Notes: * Includes heat transported by CCHPs only

\section{Summary and Conclusions}

High-efficiency RPSs, such as the SRG110, can be very flexible in their configuration and provide operation as both a power source and heat source in a range of environments. This paper outlined several methods that can be employed to utilize the waste heat from a high-efficiency RPS. In all of the examples, the amount of waste heat recovered from the high-efficiency RPS was typical of the usable waste heat recovered from a low-efficiency RTG. The advantages of using a high-efficiency power source extend past the benefit of reduced fuel content. The thermal advantages of having a lower surface temperature allow for greater flexibility and more direct use of the waste heat for spacecraft thermal management, including elimination of the need for additional radiation heat exchangers. Additionally, the lower surface temperatures of the high-efficiency RPS make many types of component thermal shields unnecessary. The cost savings for high-efficiency sources include not only the fuel material costs, but also all the costs associated with design, safety verification, and heat source processing. Mass savings are also realized by high-efficiency RPSs through reduction in hardware and lower heat source mass; the benefit of which could be realized by using smaller launch vehicles or increasing the scientific payload.

Examples of extreme mission environments were investigated, and it was shown that the higherefficiency systems, like the SRG110, can meet the same electrical power and usable waste heat requirements as an RTG for less cost and lower mass, while providing more flexibility for spacecraft design and easier integration with the spacecraft. 


\section{References}

1. Planning \& Human Systems, Inc., Atomic Power in Space: A History, Department of Energy, Washington, DC, 1987.

2. Lockheed Martin Astronautics Valley Forge Operations, "Final Technical Report: GPHS-RTGs in Support of the Cassini Mission," Document No. RR18, US Department of Energy, Oakland, CA, 1998.

3. National Aeronautics and Space Administration (NASA), "New Horizons AO, Radioisotope Power System (RPS) Information Summary," Washington, DC, October 2003.

4. Department of Energy, "Space Radioisotope Power Systems; Stirling Radioisotope Generator," April, 2002, URL: http://www.ne.doe.gov/pdf/stirling.pdf [cited April 25, 2005].

5. Mauzy, A. (ed.), "NMT's Contributions to the Cassini Saturn Mission Follow Division's Space Exploration Tradition," The Actinide Research Quarterly, US Department of Energy, Los Alamos National Laboratory, Fall 1996. pp. 1-10.

6. Leberton, J.P., and Matson, D.L., "Huygens: Science, Payload \& Mission", European Space Agency (ESA), ESA-SP-1177, Noordwijk, The Netherlands, 1997.

7. Department of Energy, "Nuclear Power in Space," DOE/NE-0071, Department of Energy Office of Nuclear Energy, Science and Technology, Washington, DC.

8. Birur, G.C., Bhandari, P., and Gram, M.B., "Mechanical Pumped Cooling Loop for Spacecraft Thermal Control," SAE Technical Paper No. 961488, 26th International Conference on Environmental Systems, Monterey, CA, July 8-11, 1996.

9. Birur, G.C., and Bhandari, P., "Mars Pathfinder Active Heat Rejection System: Successful Flight Demonstration of a Mechanically Pumped Cooling Loop," SAE Technical Paper No. 981684, 28th International Conference on Environmental Systems, Danvers, MA, July 13-16, 1998.

10. Ganapathi, G.B., Birur, G.C., Tsuyuki, G.T., McGrath, P.L., and Patzold, J. D., "Active Heat Rejection System on Mars Exploration Rover-Design Changes from Mars Pathfinder," Space Technology and Applications International Forum (STAIF-2003) edited by M. El-Genk, AIP Conference Proceedings 654, Melville, New York, 2003, pp. 206-217.

11. Abelson, R.D. (ed.), "Enabling Exploration with Small Radioisotope Power Systems," NASA Jet Propulsion Laboratory, JPL Pub 04-10, September, 2004.

12. Abelson, R.D. (ed.), "Expanding Frontiers with Standard Radioisotope Power Systems," NASA Jet Propulsion Laboratory, JPL D-28902, January, 2004.

13. Panczak, T.D., Ring, S.G., Welch, M.J., and Johnson, D., "Thermal Desktop ${ }^{\circledR}$ Users Manual, Version 4.7," C\&R Technologies, Littleton, CO, 2004. 
Public reporting burden for this collection of information is estimated to average 1 hour per response, including the time for reviewing instructions, searching existing data sources, gathering and maintaining the data needed, and completing and reviewing the collection of information. Send comments regarding this burden estimate or any other aspect of this collection of information, including suggestions for reducing this burden, to Washington Headquarters Services, Directorate for Information Operations and Reports, 1215 Jefferson Davis Highway, Suite 1204, Arlington, VA 22202-4302, and to the Office of Management and Budget, Paperwork Reduction Project (0704-0188), Washington, DC 20503.

\section{\begin{tabular}{l|l|l} 
1. AGENCY USE ONLY (Leave blank) & 2. REPORT DATE & 3. REPORT TYPE AND DATES COVERED
\end{tabular}}

\section{TITLE AND SUBTITLE}

October 2005

Technical Memorandum

Utilizing Radioisotope Power System Waste Heat for Spacecraft

Thermal Management

\section{AUTHOR(S)}

David R. Pantano, Frank Dottore, E. Wayne Tobery, Steven M. Geng,

Jeffrey G. Schreiber, and Joseph L. Palko

\section{FUNDING NUMBERS}

\section{PERFORMING ORGANIZATION NAME(S) AND ADDRESS(ES)}

National Aeronautics and Space Administration

John H. Glenn Research Center at Lewis Field

Cleveland, Ohio 44135-3191

WBS-22-972-20-01

\section{SPONSORING/MONITORING AGENCY NAME(S) AND ADDRESS(ES)}

National Aeronautics and Space Administration

Washington, DC 20546-0001

8. PERFORMING ORGANIZATION REPORT NUMBER

\section{E-15314}

\section{SUPPLEMENTARY NOTES}

Prepared for the Third International Energy Conversion Engineering Conference sponsored by the American Institute of Aeronautics and Astronautics, San Francisco, California, August 15-18, 2005. David R. Pantano, Frank Dottore, and E. Wayne Tobery, Lockheed Martin Space Systems Company, 230 Mall Boulevard, King of Prussia, Pennsylvania 19406; Steven M. Geng and Jeffrey G.

Schreiber, NASA Glenn Research Center; and Joseph L. Palko, Connecticut Reserve Technologies, Inc., 10030 Greenwich Drive, Strongsville, Ohio 44136. Responsible person, Steven M. Geng, organization code RPT, 216-433-6145.

12a. DISTRIBUTION/AVAILABILITY STATEMENT 12b. DISTRIBUTION CODE

Unclassified - Unlimited

Subject Category: 34

Available electronically at http://gltrs.grc.nasa.gov

This publication is available from the NASA Center for AeroSpace Information, 301-621-0390.

\section{ABSTRACT (Maximum 200 words)}

An advantage of using a Radioisotope Power System (RPS) for deep space or planetary surface missions is the readily available waste heat, which can be used for a number of beneficial purposes including: maintaining electronic components within a controlled temperature range, warming propulsion tanks and mobility actuators, and maintaining liquid propellants above their freezing temperature. Previous missions using Radioisotope Thermoelectric Generators (RTGs) dissipated large quantities of waste heat due to the low efficiency of the thermoelectric conversion technology. The next generation RPSs, such as the 110-Watt Stirling Radioisotope Generator (SRG110) will have higher conversion efficiencies, thereby rejecting less waste heat at a lower temperature and may require alternate approaches to transferring waste heat to the spacecraft. RTGs, with efficiencies of $\sim 6$ to 7 percent, reject their waste heat at the relatively high heat rejection temperature of $200{ }^{\circ} \mathrm{C}$. This is an advantage when rejecting heat to space; however, transferring heat to the internal spacecraft components requires a large and heavy radiator heat exchanger. At the same time, sensitive spacecraft instruments must be shielded from the thermal radiation of the RTG. The SRG110, with an efficiency around 22 percent and $50{ }^{\circ} \mathrm{C}$ nominal housing surface temperature, can readily transfer the available waste heat directly via heat pipes, thermal straps, or fluid loops. The lower temperatures associated with the SRG110 avoid the chances of overheating other scientific components, eliminating the need for thermal shields. This provides the spacecraft designers more flexibility when locating the generator for a specific mission. A common misconception with high-efficiency systems is that there is not enough waste heat for spacecraft thermal management. This paper will dispel this misconception and investigate the use of a high-efficiency SRG110 for spacecraft thermal management and outline potential methods of waste heat utilization in several conceptual missions (Lunar Rover, Mars Rover, and Titan Lander). The advantages associated with the SRG110 as they relate to ease of assembly, less complex interfaces, and overall mass savings for a spacecraft will be highlighted.

14. SUBJECT TERMS

Spacecraft temperature; Temperature control; Heat transfer; Stirling cycle 15. NUMBER OF PAGES 19

\begin{tabular}{|c|c|c|}
\hline $\begin{array}{c}\text { 17. SECURITY CLASSIFICATION } \\
\text { OF REPORT } \\
\text { Unclassified }\end{array}$ & $\begin{array}{c}\text { 18. SECURITY CLASSIFICATION } \\
\text { OF THIS PAGE } \\
\text { Unclassified }\end{array}$ & $\begin{array}{c}\text { 19. SECURITY CLASSIFICATION } \\
\text { OF ABSTRACT } \\
\text { Unclassified }\end{array}$ \\
\hline
\end{tabular}



